\title{
Trends in Teen Sexual Behavior
}

\author{
Douglas J. Besharov and Karen N. Gardiner
}

\begin{abstract}
At least until the last few years, the proportion of teenagers who have had sex rose steadily, and they are more likely to use contraceptives than their earlier counterparts. Underlying this general trend has been an increase in sexual activity among young teens-ages 15 and under-as well as middle-class and white teenagers. Contraceptive use has risen also, probably because of the fear of AIDS and the increased sexual activity among white and middle-class teenagers.

Because more teenagers were using contraceptives, the pregnancy rate per 1,000 sexually active teenagers actually declined during the 1980s, even as more teenagers were having sex. Nevertheless, contraceptive use is far from perfect, leading to high levels of abortion, sexually transmitted diseases, and nonmarital births. The challenge for school-based programs is to pursue two simultaneous goals: lower the level of sexual activity and raise the rate of contraceptive use among those who have sex.
\end{abstract}

\section{Introduction}

When President Clinton appointed his first surgeon general, the controversial and outspoken Joycelyn Elders, he signaled his intention to make an issue of teenage pregnancy and parenthood. Dr. Elders left Washington, but the issue has remained. The past year, for example, witnessed the creation of a multimillion dollar national campaign to reduce teenage pregnancy and welfare reform legislation that earmarked one-quarter billion dollars for abstinence education.

There is nothing new about teenage sex. In the past, however, it was largely confined to married teenagers, or those soon to be married, and thus was not considered a problem. But today, teenagers are much less likely than in the past to get married. In 1993, for example, the average age at first marriage for women was 24.5 years and 26.5 years for men.

The decline in teenage marriages, however, has not led to a corresponding drop in teenage sexual activity. During the 1970s and 1980s at least, more teenagers became sexually active, and they had sex more frequently, with more partners, and at younger ages. Newly-released data, however, indicate that there may have been a decline in 
teenage sexual activity. According to the 1995 National Survey of Family Growth, the proportion of sexually active females ages 15 to 19 fell $8 \%$ between 1988 and 1995 (Abma et al., 1997). The 1995 National Survey of Adolescent Males also found an 8\% decline in sexual activity among teenage males since 1988 (Sonenstein \& Ku, 1997). This is welcome news after the rate of sexual activity seemed to rise inexorably over the past two decades. The new data contained another positive finding: The proportion of sexually active teenagers using contraception rose dramatically.

These data may signal the start of a trend towards less sex and more contraceptive use among teenagers. Further analysis of the data, as well as additional studies, will be needed to draw a definitive conclusion. But even if these early suggestions of a turnaround in teenage sexual activity are valid, there is still much room for improvement. About half of male and female teenagers have had sex, including about $20 \%$ of 15 -yearold females. And contraceptive use is far from perfect. As a result, each year there are about 1 million pregnancies resulting in approximately 400,000 abortions, 500,000 births, and 100,000 miscarriages. Of the births, over $70 \%$ are out of wedlock, putting those young mothers at risk of long-term welfare dependency. And about 3 million teenagers contract a sexually transmitted disease (STD) such as chlamydia, gonorrhea, and even AIDS.

Most people are unhappy about sexual activity among younger adolescents, but disagreement is more widespread about sexual activity among older teenagers. (We will not try to draw the age line.) Some believe that sex outside of marriage undermines traditional moral values or can be psychologically damaging to adolescents. Others are concerned that teenagers are relatively poor contraceptors.

Most agree that teenagers tend to be reckless in their behavior, and unprotected sex is just one of a host of risky behaviors in which they engage. But even for those who are always careful, accidents can happen and contraceptives can fail. Moreover, some teenagers are exploited or coerced into having sex and thus have little control over contraception.

Today, several major policy issues surround teenage sexual activity: (1) how can the level of such activity be reduced, especially among younger teenagers? and (2) how can sexually active teenagers be better contraceptors? To provide a context for considering these two questions, this paper presents an overview of major trends.

\section{The Data}

Five principal sources supply information about the sexual practices of teenagers: the National Survey of Family Growth (NSFG), a national in-person survey of women ages 15 to 44 conducted in 1982, 1988, and 1995 (Forrest \& Singh, 1990; CDC, 1991; Abma et 
al., 1997); the National Survey of Adolescent Males (NSAM), a longitudinal survey of males ages 15 to 19 conducted in 1988, 1991, and $1995^{1}$ (Sonenstein, Pleck, \& Ku, 1989 \& 1991; Sonenstein \& Ku, 1997); the National Survey of Young Men (NSYM), a 1979 survey of 17- to-19-year-olds (Sonenstein, Pleck, \& Ku, 1989); and the Youth Risk Behavior Survey (YRBS), a 1990 questionnaire-based survey of 11,631 males and females in grades 9 to 12 conducted by the Centers for Disease Control (CDC, 1992). Additional data are provided by the 1991 National Survey of Men (NSM), a nationally representative sample of 3,300 males ages 20 to 39 (Billy et al., 1993).

All these surveys are based on self-reports and must be interpreted with caution. Recall bias, for example, can be a problem. A 44-year-old may not remember the exact circumstances surrounding her first sexual experience. Moreover, because many interviews are conducted in person, the teenager or adult being interviewed may give the answer that he thinks is socially correct. Thus, the following statistics should be viewed as indicative of trends rather than as precise measures of current behavior.

\section{More and Earlier Sex}

Since 1970, nonmarital sexual activity among teenagers has increased sharply. The NSFG asked women ages 15 to 44 to recall their first premarital sexual experience. About $40 \%$ of the females who were 18 years old in 1970 said that they had had sex by that age. But $56 \%$ of the females who were 18 years old in 1980 said they had had sex by that age. For those who were 18 in 1988, the proportion had risen to 70\% (CDC, 1991). Premarital teenage sex has always been more prevalent among males. According to the NSM, 55\% of males who were 18 years old in 1968-1970 had had sex, compared with 64\% in 19771979 and 73\% in 1986-1988 (Alan Guttmacher Institute, 1994) (see chart 1).

\section{CHART 1 HERE}

As mentioned above, the 1995 NSFG reports a reversal in this trend. According to the 1995 NSFG, the proportion of 18-year-old females who reported having had sex fell $10 \%$, to $63 \%$ (Abma et al., 1997).

Teenagers were not only more likely to become sexually active in the 1970s and 1980s, but they were experiencing sex at younger ages. As mentioned above, the percentage of 18-year-old females who had had sex increased about 75\% between 1970 and 1988 . The percentage of sexually experienced 15 -year-old females, however,

\footnotetext{
${ }^{1}$ As this paper was going to the press, data analysis from the 1995 National Survey of Family Growth and the 1995 National Survey of Adolescent Males was limited. The data available to us have been incorporated into this paper.
} 
multiplied more than fivefold during the same period, from less than $5 \%$ to $26 \%$. (See chart 2).

The 1995 data, however, show that the proportion of teenage females who reported that they have had sex fell or levelled off among all age groups (except 16-yearolds). As noted above, sexual activity decreased about $10 \%$ among 18 -year-olds (from $69 \%$ to $63 \%)$, stayed virtually the same among 17 -year-olds ( $51 \%$ vs. $50 \%)$, and declined almost $20 \%$ among 15-year-olds (from $26 \%$ to 21\%) (Abma et al., 1997). ${ }^{2}$

\section{CHART 2 HERE}

Partly because they were beginning sex at earlier ages, the majority of teenagers in the late 1980s reported having had sex with more than one partner (see chart 3). According to the 1988 NSFG, the proportion of sexually active 15-to-19-year-old females who had more than one lifetime partner increased from 38\% in 1971 to $61 \%$ in 1988 (Smith, 1994). The 1990 YRBS found that about 7\% of 9th-grade females and 19\% of males the same age had had intercourse with four or more different partners. By the 12 th grade, $17 \%$ of females and $38 \%$ of males reported having had four or more sexual partners.

\section{CHART 3 HERE}

The overall figures, however, tend to overstate teenage sexual activity because they include all youngsters who have ever had sex, even once. Analyzing data from the NSAM, for example, Sonenstein and her colleagues found that the average 15-to-19-yearold male was abstinent for six months each year. Fifteen-year-old males spent an average of eight months abstinent (Sonenstein, Pleck, \& Ku, 1991).

Moreover, these are aggregate rates, and they mask important differences among various groups in our society. Low-income and African-American teenagers have always had higher rates of sexual activity than nonpoor and white ones, and still do. But the gap

\footnotetext{
${ }^{2}$ We are aware that a different study found that the increase in sexual activity among young teenagers continued into the early 1990s. Using a different survey methodology, the CDC's Youth Risk Behavior Survey (YRBS) found that in 1990, 32\% of 9th-grade females (ages 14 and 15) reported ever having had sex, as did $49 \%$ of the males in the same grade. At the same time, the proportion of 12th-grade females and males (ages 17 and 18) who reported ever engaging in sex remained at about 1988 levels. Unlike the NSFG and NSAM, however, which are face-to-face interviews, the YRBS is a paper-and-pencil questionnaire administered to classrooms of students. No one knows whether this format leads to over- or underreporting of high-risk behaviors. But the different methodology makes a comparison between these figures and those from the NSFG and NSAM problematic.
} 
is narrowing — at least among older teenagers.

Rates of sexual activity of poor and nonpoor females are converging, because sexual activity has become more prevalent among middle-class and older teenagers. According to the NSFG, between 1982 and 1988 the proportion of sexually active 15-to 19 -year-old females in families with incomes equal to or greater than $200 \%$ of the poverty line increased from $39 \%$ to $50 \%$. At the same time, the proportion of females from poorer families (those earning less than $200 \%$ of the poverty line) who had ever had sex remained stable at 56\% (Forrest \& Singh, 1990) (see chart 4).

\section{CHART 4 HERE}

The differences in rates of sexual activity between white and black female teenagers also narrowed during the 1980s. Analysis of the NSFG found that between 1970 and 1988, the percentage of 15- to 19-year-old black females who reported having had sex rose from $49 \%$ to 59\%. Among white females, the rate almost doubled between 1970 and 1988, from $27 \%$ to $51 \%$ (CDC, 1991). But these rates converged mostly because older black and white females (ages 18 and 19) were having sex in similar proportions: $76 \%$ and $73 \%$, respectively (see chart 5).

\section{CHART 5 HERE}

Although more analyses will be needed to reach a definitive conclusion, it appears that the black/white differential among females grew in the 1990s. According to the 1995 data, the proportion of black 15- to 19-year-old females who reported having had sex stayed at the 1988 level. The proportion of sexually active white females, however, fell slightly, to 47 percent (Abma et al., 1997). Even among older black and white females (ages 18 and 19), the gap in sexual experience widened slightly. The proportion of blacks who had had sex dropped one percentage point (to 75\%), while the white rate fell 5 percentage points (to 68\%).

Moreover, even before these recent data, it appeared that there were substantial racial differences in sexual experience among younger teenagers (both boys and girls). According to the 1988 NSFG, one-third of black 15-year-old females reported that they had had sex, compared with $24 \%$ of their white counterparts (Moore, 1992).

Among males, the proportion of black 17-to-19-year-olds who had had sex increased from $71 \%$ in 1979 to $88 \%$ in 1988, while the rate for white males increased from $64 \%$ to $73 \%$ (Sonenstein, Pleck, \& Ku, 1989). Again, rates of sexual activity are closer for older teenagers. The 1988 NSAM found that $96 \%$ of black males reported that they had had sex by age 19 compared with $85 \%$ of white males. The gap was wider among 15 year-olds: $64 \%$ of blacks versus $33 \%$ of whites reported already having had sex (Moore, 1992). The foregoing data measure the proportion of teenagers who have ever had sex. 
Black teenager males, however, tend to report having had more partners and more frequent sex. These racial differences also are highly associated with income differences, so they should be interpreted with care.

\section{More Careful Sex}

Contrary to conventional wisdom, it appears that teenagers have become more careful about contraception. The proportion of teenage females who reported using a method of contraception at first intercourse, for example, increased from $48 \%$ in 1982 to $65 \%$ in 1988 to 77\% in 1995 (Forrest \& Singh, 1990; Abma et al., 1997). This is important because studies indicate that half of premarital first pregnancies to teenagers occur within six months of initiating sex, and one-sixth occur within a month of first sex (Zabin et al., 1979).

Moreover, use of contraceptives at first sex increased among both white and black teenagers. Although whites were still more likely to report having used a contraceptive, the rate of increase since 1988 was greater among blacks. (see chart 6). The proportion of white females who reported using a method of contraception at first intercourse increased from $55 \%$ in 1982 to $69 \%$ in 1988. By 1995, use rose to $83 \%$, a $20 \%$ increase. Among black females, the proportion using contraception at first intercourse increased from $36 \%$ to $54 \%$ between 1982 and 1988. By $1995,72 \%$ of black females reported using a method at first sex, a 33\% increase from 1988 (Forrest \& Singh, 1990; Abma et al., 1997).

\section{CHART 6 HERE}

Contraceptive use at first intercourse has also increased among males since the late 1980s. The 1995 NSAM found that proportion of 15- to 19-year-old males who said they relied on an "effective" method of contraception (such as a condom or oral contraceptives) increased from $62 \%$ in 1988 to $73 \%$ in 1995 (Sonenstein \& Ku, 1997).

Much of the increase in contraceptive use at first intercourse was apparently driven by condom use. The 1995 NSFG reported that $60 \%$ of females used a condom at first intercourse, an increase from $47 \%$ in 1988. By way of comparison, the proportion of females who relied on oral contraceptives increased from $8 \%$ to $11 \%$ (Forrest \& Singh, 1990; Abma et al., 1997). Among males, condom use at first intercourse rose from 55\% in 1988 to $69 \%$ in 1995 (Sonenstein \& Ku, 1997).

The 1995 findings concur with data from the 1980s that indicated the increased use of contraception was apparently driven, at least in part, by fear of AIDS and other sexually transmitted diseases. In the mid-1980s, a major public health campaign was waged nationwide that promoted the use of barrier methods of contraception as a way of avoiding STDs. Many teenagers heard this message. According to the NSAM, between 
1979 and 1988, the proportion of teenage males who reported using condoms during their last sexual experience almost tripled, from $21 \%$ to $57 \%$ (Sonenstein, Pleck, \& Ku, 1989).

\section{CHART 7 HERE}

Increased condom use was also reflected in the NSFG data. The proportion of female teenagers who reported that they relied on condoms (not just at last intercourse) increased almost $75 \%$ between 1982 and 1988 (from 15\% to 26\%).

Increased contraception was also the result of more sexual activity among middleclass and white youths, described above. These groups have traditionally been more careful about their sexual practices. While contraceptive use at first sex increased among all socioeconomic groups, teenagers from middle-class families were more likely to use contraception at first intercourse. According to the NSFG, the proportion of middle-class teenagers who reported using contraception at first sex increased between 1982 and 1988, from $57 \%$ to $73 \%$. During the same period, use at first intercourse among teenagers from poorer families increased from $40 \%$ to $58 \%$ (Forrest \& Singh, 1990).

\section{CHART 8 HERE}

Because teenagers are more likely to use birth control, the substantial increase in teenage sexual activity has not been matched with an equivalent increase in the number of teenage conceptions. In fact, the absolute number of pregnancies increased by about $21 \%$ between 1975 and 1988, even as there was a 39\% increase in the number of female teenagers who reported engaging in sex. The pregnancy rate among sexually active teenagers (as opposed to the entire population of teenagers) actually declined between 1982 and 1987, from 271 per 1,000 teenagers to 243 per 1,000 (Forrest \& Singh, 1990).

In fact, one could construct a crude "teen conception index" that measures the changing rate of conception (composed of abortions, miscarriages, and births) among sexually active but unmarried teenagers. This index stood at 0.87 in 1988, representing a 13\% decline from 1975. Most of this decline occurred between 1985 and 1988 as contraceptive use increased among all groups and as more middle-class teenagers initiated sex (Besharov \& Gardiner, 1993) ${ }^{3}$ (see chart 8). If, as the 1995 data indicate, levels of

3 Conception index sources: for abortions, Stanley K. Henshaw, the Alan Guttmacher Institute, based on $97 \%$ of abortions to unmarried teens. For miscarriages: Stanley K. Henshaw, the Alan Guttmacher Institute, assuming that all were to unmarried teens. For out-of-wedlock births: Stephanie Ventura, National Center for Health Statistics. For the total number of unmarried females ages 15-19: the Census Bureau, Division of Marriage and Family. For the percentage of unmarried, sexually active females ages 15-19: the National Center for Health Statistics, National Survey of Family Growth. 
teenage contraceptive use rose, we would expect the index to drop even further.

\section{Contraceptive Nonuse and Misuse}

Despite the improvements in contraceptive use, however, many teenagers still use contraceptives inconsistently, or not at all. Although contraceptive use at first intercourse did increase during the 1980 s, the NSFG reports that in $1988,31 \%$ of white female teenagers and $41 \%$ of black ones reported that they did not use any method at that time. Moreover, in that year, $20 \%$ o sexually active female teenagers reported that they were not using any form of contraception (Forrest \& Singh, 1990). Contraceptive use at first intercourse continued to increase during the 1990s. The proportion of teenage females engaging in unprotected first sex fell sharply, to $17 \%$ of whites and $28 \%$ of blacks. There is room for substantial progress on this front, however. Almost one in five white females and one in three black females were not using birth control during their first sexual experience, thus putting themselves at risk of pregnancy and disease (Abma et al., 1997).

The more risky the teenager's general behavior is, the greater the likelihood is of riskyand early-sex (see chart 9). Donald Orr and his colleagues at the University of Indiana studied condom use among inner-city female teenagers in Indianapolis and found that only about $50 \%$ of them reported that their partners had ever used condoms. Significantly, the figure fell to only $29 \%$ among "risk-takers," defined as drug or alcohol users, school dropouts, and those who committed minor delinquencies (Orr et al., 1992).

\section{CHART 9 HERE}

As chart 10 indicates, sex among young teenagers is also associated with other risk-taking behaviors such as smoking, drinking, and using drugs. The YRBS found, for example, that the proportion of 14- and 15-year-olds who had had sex was $87 \%$ among those who smoked marijuana regularly, compared with $36 \%$ of those who never did so (AGI, 1994).

\section{CHART 10 HERE}

Moreover, many teenagers report that they were using a contraceptive at the time they got pregnant but that it failed. As chart 11 shows, contraceptive failure rates within the first year of use are higher for teenagers, particularly poor ones, than among "typical users" in the general population. Contraceptive failure rates are often presented in two

For conception index calculations: For the base year (1975), total pregnancies were divided by total number sexually active. For subsequent years, total pregnancies were divided by total number sexually active for each year, then divided by the base year calculation. 
ways: (1) failure rates in clinical trials (usually involving married couples); and (2) the failure rates of "typical users" (based on surveys of the general population). James Trussell of Princeton University estimates, for example, that the clinical failure rate of the condom is $2 \%$. Twelve percent of typical users, however, experience a condom failure in their first year of use, compared with $13 \%$ of never-married, middle-class teens and $27 \%$ of poor ones. The difference in failure rates is even greater for less effective methods. About one in five typical users will experience a failure while relying on periodic abstinence. The rates for never-married, middle-class teenagers and poor teenagers are 27\% and 52\%, respectively (Trussell et al., 1990; Jones \& Forrest, 1992).

\section{CHART 11 HERE}

\section{Coerced or Exploitative Sex}

Another obstacle to both abstinence and safer sex is the apparently high level of coerced and exploitative sex. Kristin Moore of Child Trends analyzed data from the 1987 National Survey of Children and found that three-quarters of the females who had had intercourse before age 14 and $60 \%$ of those who had had sex before age 15 reported having had sex involuntarily (AGI, 1994). The National Health and Social Life Survey also tried to gauge the "wantedness" of first sex. Fewer women than men reported that their first sexual experience was wanted (71\% vs. 92\%) (Laumann et al., 1994).

In recent years, there has been growing concern among policy makers and the public that a large number of births to teenage mothers $-50 \%$ by some accounts-involve a father who is not himself a teenager. This belief has led to a renewed interest in statutory rape laws. Society should certainly be concerned about exploitative relationships. But the $50 \%$ figure is misleading because it includes many parents who are close in age but happen to fall on opposite sides of the 20 -year mark. In other words, the bulk of these situations involve mothers in their late teens and fathers in their early-to mid-20s.

Laura Lindberg and her colleagues at the Urban Institute give us a more precise picture of what is happening. Using the 1988 National Maternal and Infant Health Survey, they estimated the number of births to unmarried minors (ages 15 to 17) that involved men

five or more years older. (They chose a five-year difference because that is the measure of statutory rape in many states.) The authors found that $8 \%$ of births to 15- to-19-year-olds involved unmarried minors and older males. Only 3\% of all nonmarital births in 1988 did so (Lindberg et al., 1997).

The authors did find, however, that the younger the mother, the more likely that the relationship involved an older man. About $40 \%$ of 15 -year-old mothers had a partner five or more years older, compared with $27 \%$ of 16 -year-olds and $24 \%$ of 17 -year-olds. (Births to 15-year-olds, however, represent only $13 \%$ of all births to 15 -to-17-year-olds.) 
These findings are corroborated by birth records. Mike Males of the University of California at Irvine studied 1990 California birth certificates and found that when the mothers were ages 11 to 12 , the fathers of their babies were, on average, 10 years older. Among mothers ages 13 to 14, the fathers averaged 4.6 years older (Males, 1993) (see chart 12).

\section{CHART 12 HERE}

\section{Costs}

The costs to society of unprotected sex are considerable. In 1992, for example, there were about 1 million pregnancies, resulting in over 300,000 abortions, 134,000 miscarriages, and 500,000 live births (Henshaw, 1992). Of the births, 70\% were out of wedlock (National Center for Health Statistics, 1994). And about 3 million teenagers suffered from a sexually transmitted disease such as chlamydia, syphilis, gonorrhea, herpes, and even AIDS (AGI, 1994).

Abortion: The Abortion Provider Survey, performed periodically by AGI, collects information about abortions and the clinics that provide them. According to AGI, about $35 \%$ of all teenage pregnancies now end in abortion and another $14 \%$ in miscarriage. (Unmarried teenagers account for about $97 \%$ of all abortions to teens.) Thus, of the 1.5 million abortions in 1992, over 300,000 were performed on teenagers. In the 11 years between 1973 and 1984, the abortion rate for females ages 15 to 19 almost doubled, from 23 to 43 per 1,000 (AGI, 1994). Between 1984 and 1992, the rate stabilized.

\section{CHART 13 HERE}

Chart 13 depicts the proportion of abortions by income subgroup. Poor teenagers had about the same proportion of abortions (32\%) as middle-income teenagers. (These numbers reflect the distribution for all women.) These figures, however, are misleading because middle-income teenagers account for a larger proportion of the general population. In 1987, AGI calculated an abortion index by dividing the proportion of abortion patients in a subgroup by the proportion of women ages 15 to 44 in the same subgroup. (Estimates were not available for teenagers.) An index of 1.0 reflected the national average. The researchers found that the index for poor women stood at 2.22, meaning that they had abortions at a rate more than twice the national average. The index for middle-class women, 0.59 , indicated that they had abortions at about half the national rate (Henshaw and Silverman, 1988).

Nonmarital births: According to the National Center for Health Statistics, more than 350,000 babies were born to unmarried 15-to-19-year-olds in 1992. Although the 
total number of births to teenagers declined between 1970 and 1992, the proportion born out of wedlock more than doubled (from $29 \%$ to $70 \%$ ), and the teenage nonmarital birth rate increased from about 22 per 1,000 to 45 per 1,000 (Moore, 1994; NCHS, 1996).

Teenage mothers now account for about $30 \%$ of all out-of-wedlock births, but this figure understates the impact of unwed teen parenthood on the nation's nonmarital birth rate. Moore and her colleagues at Child Trends found that $60 \%$ of women who had a nonmarital birth in the 1980s had their first birth as a teenager (U.S. Health and Human Services, 1995).

\section{CHART 14 HERE}

The trend in births to unmarried teenagers diverges for whites and blacks. Among whites, both the number of births and the proportion of births to teenagers that are out of wedlock have steadily increased (see chart 14). Between 1965 and 1994, for example, the number of such births increased almost fourfold, from 49,000 to 235,000. The proportion of births out of wedlock to white teenagers also increased sharply between 1965 and 1994, from 7\% to $67 \%$. As chart 15 shows, the number of nonmarital births to black teenagers rose between the mid-1960s and mid-1970s, before stabilizing —or perhaps hitting a ceiling. The proportion of black teenage births that were out of wedlock increased from $51 \%$ in 1965 to $95 \%$ in 1994.

\section{CHART 15 HERE}

The differential impact of these out-of-wedlock birth rates on the white and the black communities is too great to be ignored. According to a 1988 National Center for Health Statistics report, about $18 \%$ of females had had at least one child before they turned 20 (NCHS, 1988). The proportion of teenagers who had had a birth differed widely by race: $35 \%$ of blacks and $15 \%$ of whites. When one considers that $91 \%$ of births to black teenagers were out of wedlock, compared with a much lower $53 \%$ of white ones, one can crudely estimate that $31 \%$ of black teenagers and $8 \%$ of whites had had at least one nonmarital birth during their teenage years.

Welfare receipt: About $50 \%$ of all teenage mothers receive welfare within one year of the birth of their first child; $77 \%$ do so within five years, according to a Congressional Budget Office (CBO) analysis of the National Longitudinal Survey of Youth. Families begun by teenagers (married or unmarried) account for the majority of welfare expenditures in this country. According to Moore of Child Trends, 59\% of women currently receiving Aid to Families with Dependent Children were 19 or younger when they had their first birth. The Robin Hood Foundation report, Kids Having Kids, estimates that adolescent childbearing itself (not including older women who had their first child as a teenager) costs society about $\$ 7$ billion each year in increased welfare and food stamp benefits, medical care, foster care, and loss of tax revenue (Maynard, 1996). 


\section{TABLE 1 HERE}

Welfare recipiency is more a function of a mother's age and marital status than of her race (see table 1). According to the NLSY, about the same proportion of white and black unmarried adolescent mothers go on welfare within one year of the birth of their first child. After five years, black unmarried mothers have a somewhat higher rate of welfare recipiency than whites ( $84 \%$ vs. $72 \%$ ), but various demographic factors - such as family income, educational attainment, and family structure-likely account for this relatively small difference.

Sexually transmitted diseases: About 3 million teenagers-or one in four sexually active teenagers - become infected with sexually transmitted diseases each year, according to the CDC. Teenagers account for $25 \%$ of all new cases annually. AGI reports that since the mid-1980s, those female teenagers who were tested for disease were increasingly more likely to test positive than in the past. Of those seeking tests, up to $29 \%$ of females tested positive for chlamydia (as did about $10 \%$ of males), up to $15 \%$ tested positive for the human papillomavirus, and reported cases of syphilis more than doubled (AGI, 1994). In a single act of unprotected sex with an infected partner, a female teenager has a $1 \%$ chance of contracting HIV (the virus that causes AIDS), a 30\% chance of getting herpes, and a 50\% chance of acquiring gonorrhea (AGI Homepage, 1996, December 5).

\section{CHART 16 HERE}

Moreover, teenagers are the age group most likely to contract an STD. For example, AGI found that there were 24 cases of gonorrhea per 1,000 sexually experienced females ages 15 to 19 in 1987 (see chart 16). Among women ages 20 to 24, the rate declined to 15 and fell rapidly with age. For women ages 25 to 29, 30 to 34, and 35 to 39, the rates were 5, 2, and 1 per thousand, respectively (Harlap et al., 1991). Except for AIDS, most STD follow a similar pattern.

If left untreated, these diseases can cause serious problems, including infertility and ectopic pregnancies. The CDC estimates that between 100,000 and 150,000 women become infertile every year because of sexually transmitted disease-related pelvic infections. AGI reports that teenage females have a higher hospitalization rate than do older women for acute pelvic inflammatory disease, most often caused by chlamydia or gonorrhea.

\section{Conclusion}

There really was a sexual revolution, as the foregoing data indicate. Society should be concerned for at least two reasons. For younger teenagers, too-early sexual experiences can be emotionally distressing and inconsistent with healthy development. For disadvantaged teens of all ages, sex too often leads to an out-of-wedlock birth and long- 
term welfare dependency. The failure of policy makers, advocates, and service providers to articulate the fundamental differences between these two aspects of the same phenomenon has led to miscommunication and unnecessary disagreement—and has stymied policy and programmatic responses. 


\section{References}

Abma, J.C., Chandra, A., Mosher, W., Peterson, L., \& Piccinino, L. (1997). "Fertility, Family Planning, and Women's Health: New Data from the 1995 National Survey of Family Growth." National Center for Health Statistics Vital Health Statistics 23(19).

Alan Guttmacher Institute. (1996). Homepage, December 5.

Alan Guttmacher Institute (AGI). (1994). Sex and America's Teenagers. New York: Alan Guttmacher Institute.

Besharov, D. J., \& Gardiner, K. N. (1993). Teen Sex: Truth and Consequences. American Enterprise 4(1), 52-59.

Billy, J.O., Tanfer, K., Grady, W., \& Klepinger, D.H. (1993). The Sexual Behavior of Men In the United States. Family Planning Perspectives 25(2), pp. 52-60.

Centers for Disease Control (CDC), Division of HIV and AIDS Prevention. (June 1996). HIV/AIDS Surveillance Report.

Centers for Disease Control (CDC). (1992). Sexual Behavior Among High School Students--United States, 1990. Morbidity and Mortality Weekly Report 40(51 \& 52), pp. 886-888.

Centers for Disease Control (CDC). (1991). Premarital Sexual Experience Among Adolescent Women-United States, 1970-1988. Morbidity and Mortality Weekly Report 39(51 \& 52), 929-932.

Congressional Budget Office. (1990). Sources of Support for Adolescent Mothers. Washington, D.C.: Government Printing Office.

Forrest, J. D., \& Singh, S. (1990). The Sexual and Reproductive Behavior of American Woman, 1982-1988. Family Planning Perspectives 22(5), 206-214.

Henshaw, S. K. (1992). U.S. Teenage Pregnancy Statistics. New York: Alan Guttmacher Institute.

Henshaw, S.K.,. \& Silverman, J. (1988). Characteristics of U.S. Abortion Patients. Family Planning Perspectives 20(4), 158-168.

Harlap, S., Kost, K., \& Forrest, J. D. (1991). Preventing Pregnancy, Protecting Health: A New Look at Birth Control Choices in the United States. New York: Alan Guttmacher Institute. 
Jones, E. F., \& Forrest, J. D. (1992). Contraceptive Failure Rates Based on the 1988 NSFG. Family Planning Perspectives 24(1), 12-19.

Laumann, E. O., Gagnon, J. H., Michael, R. T., \& Michales, S. (1994). The Social Organization of Sexuality. Chicago: University of Chicago Press.

Lindberg, L. D., Sonenstein, F., Ku, L., \& Martinez, G. (1997). Age Differences Between Minors Who Give Birth and Their Adult Partners. Family Planning Perspectives 29(2), $61-66$.

Males, M. (1993). School-age Pregnancy: Why Hasn't Prevention Worked? Journal of School Health 63(10), 429-432.

Maynard, R. (Ed.) (1996). Kids Having Kids: A Robin Hood Foundation Special Report on the Costs of Adolescent Childbearing. New York: Robin Hood Foundation.

Moore, K. (1994). In The Causes and Costs of Teen Motherhood. Conference proceedings (pp. 1-31). Washington, D.C.: American Enterprise Institute. April 5. Moore, K. (1992, January). Facts at a Glance. Washington, D.C.: Child Trends, Inc., p. 2.

National Center for Health Statistics. (1996). Advance Report on Final Natality Statistics, 1994. Monthly Vital Statistics Report 44(11), 1-88.

National Center for Health Statistics. (1994). Advance Report on Final Natality Statistics, 1992. Monthly Vital Statistics Report 43(5), 1-88.

National Center for Health Statistics. (1988). Vital Statistics of the United States.

Washington, D.C.: Government Printing Office, table 1-19.

Orr, D. P., et al. (1992). Factors Associated with Condom Use Among Sexually Active Female Adolescents. Journal of Pediatrics 120(2), pp. 311-317.

Smith, T. (1994). American Sexual Behavior. In M. Smith (Ed.). The Demography of Sexual Behavior. Menlo Park, CA: Henry J. Kaiser Family Foundation.

Sonenstein, F. \& Ku, L. (1997). Fact Sheet: New Data on Sexual Behaviors of Teenage Males (Washington, D.C.: Urban Institute, May 1).

Sonenstein, F., Pleck, J., \& Ku, L. (1991). Levels of Sexual Activity Among Adolescent Males in the United States. Unpublished paper. 
Sonenstein, F., Pleck, J., \& Ku, L. (1989). Sexual Activity, Condom Use and AIDS Awareness Among Adolescent Males. Family Planning Perspectives 21(4), pp. 152-158.

Trussell, J., Hatcher, R. A., Cates, W., Stewart, F. H., \& Kost, K. (1990). Contraceptive Failure in the United States: An Update. Studies in Family Planning 21(1), 51-54.

U.S. Department of Health and Human Services. (1995). Report to Congress on Out-ofwedlock Childbearing. Washington, D.C.: Department of Health and Human Services.

Zabin, L. S., Kanter, J. F., \& Zelnick, M. (1979). The Risk of Adolescent Pregnancy In the First Months of Intercourse. Family Planning Perspectives 11(5), 215-222. 


\section{Chart 1: Teenage Sex}

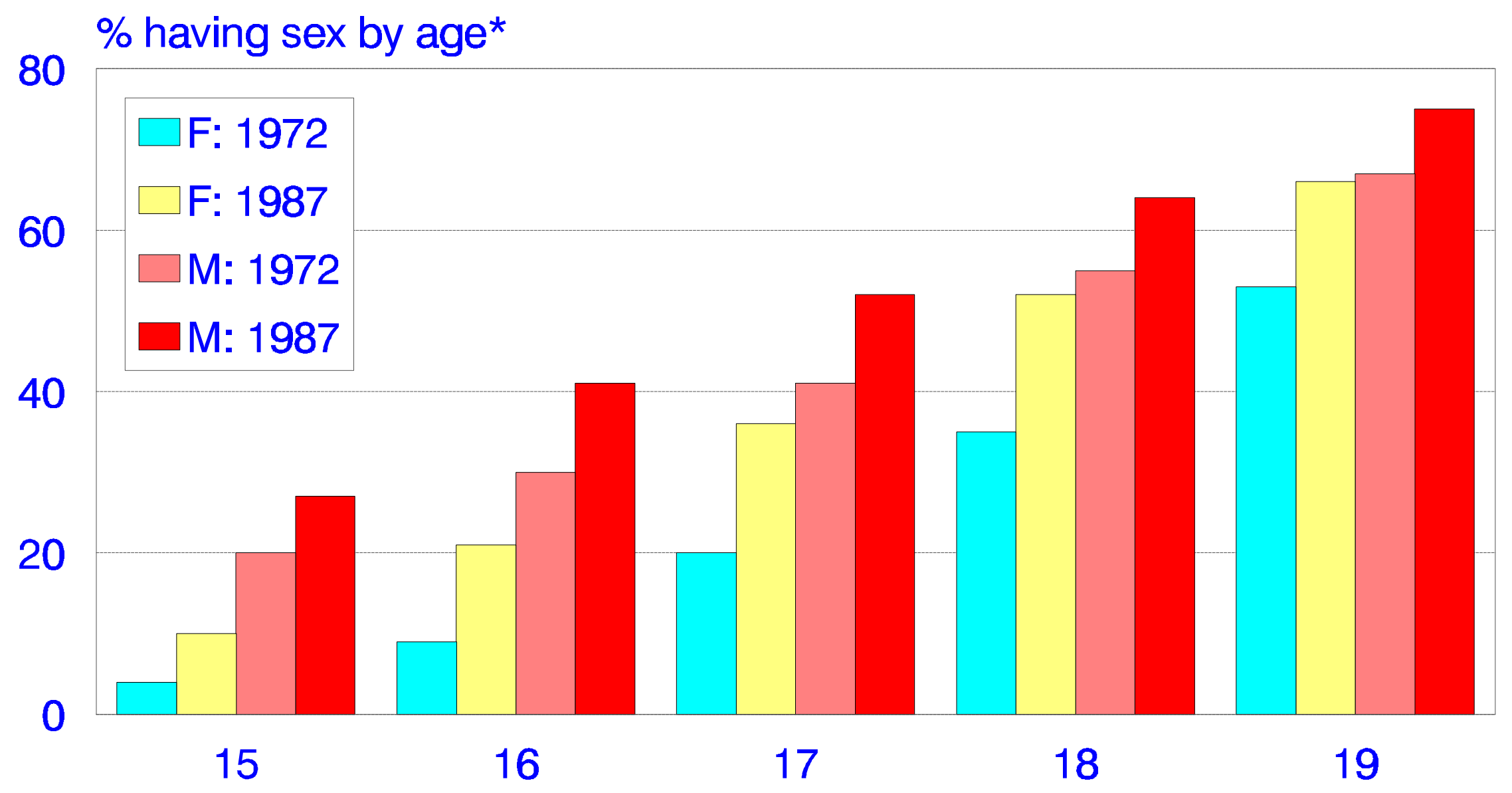

Source: Alan Guttmacher Institute, Sex and America's Teens; 1991 National Survey of Men; 1982 and 1988 National Survey of Family Growth

*Note: Calculations for males and females turning 20 in 1972 and 1987 


\section{Chart 2: Sexual Activity at Younger Ages Females Ages 15 and 17}

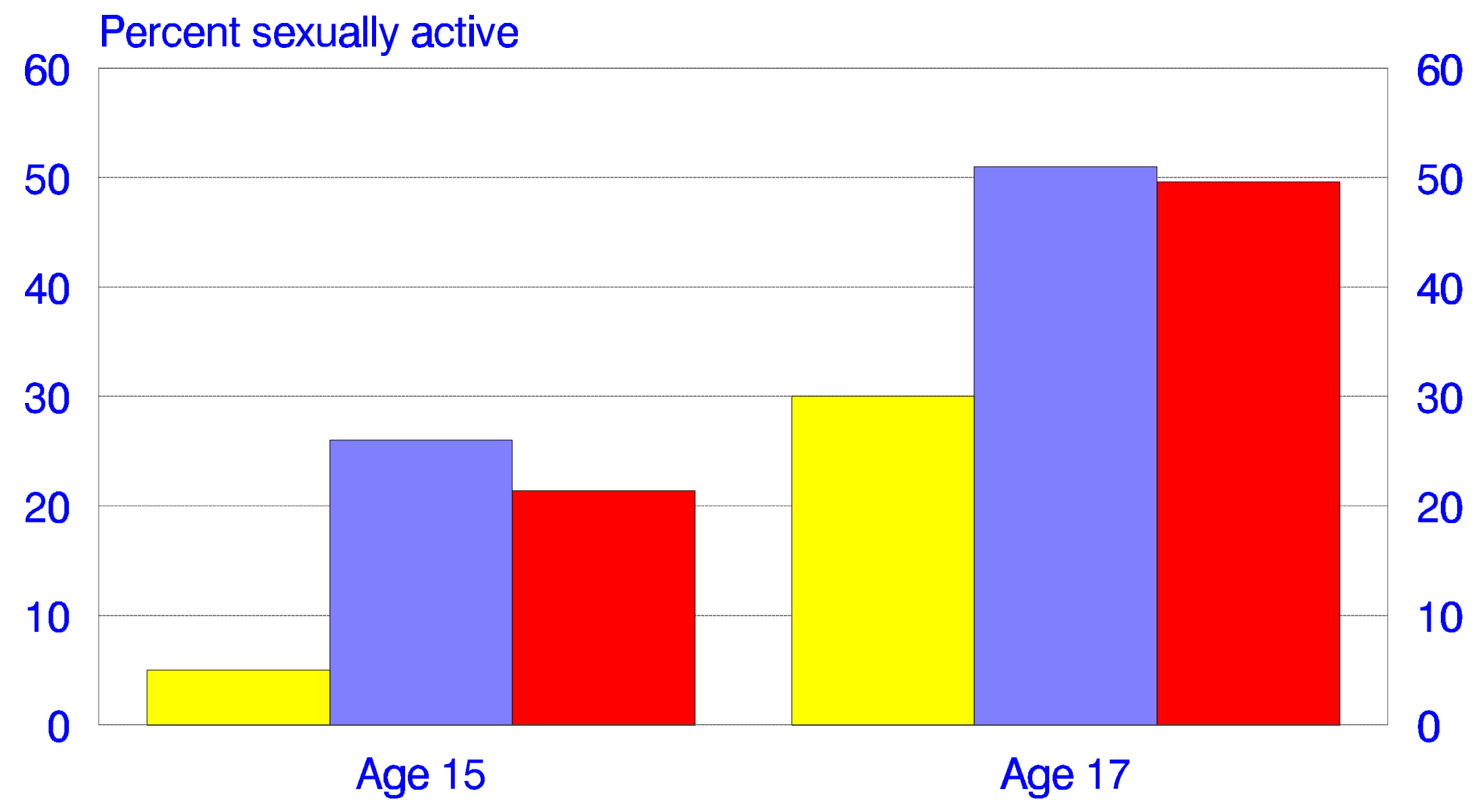

Source: National Survey of Family Growth, reported in Centers for Disease Control Morbidity and Mortality Weekly Report, vol. 39, nos. 51 \& 52 (Jan. 4, 1992) and National Center for Health Statistics Vital Health Statistics, vol. 23, no. 19 (1997). 


\section{Chart 3: Teen Sex Number of Partners}

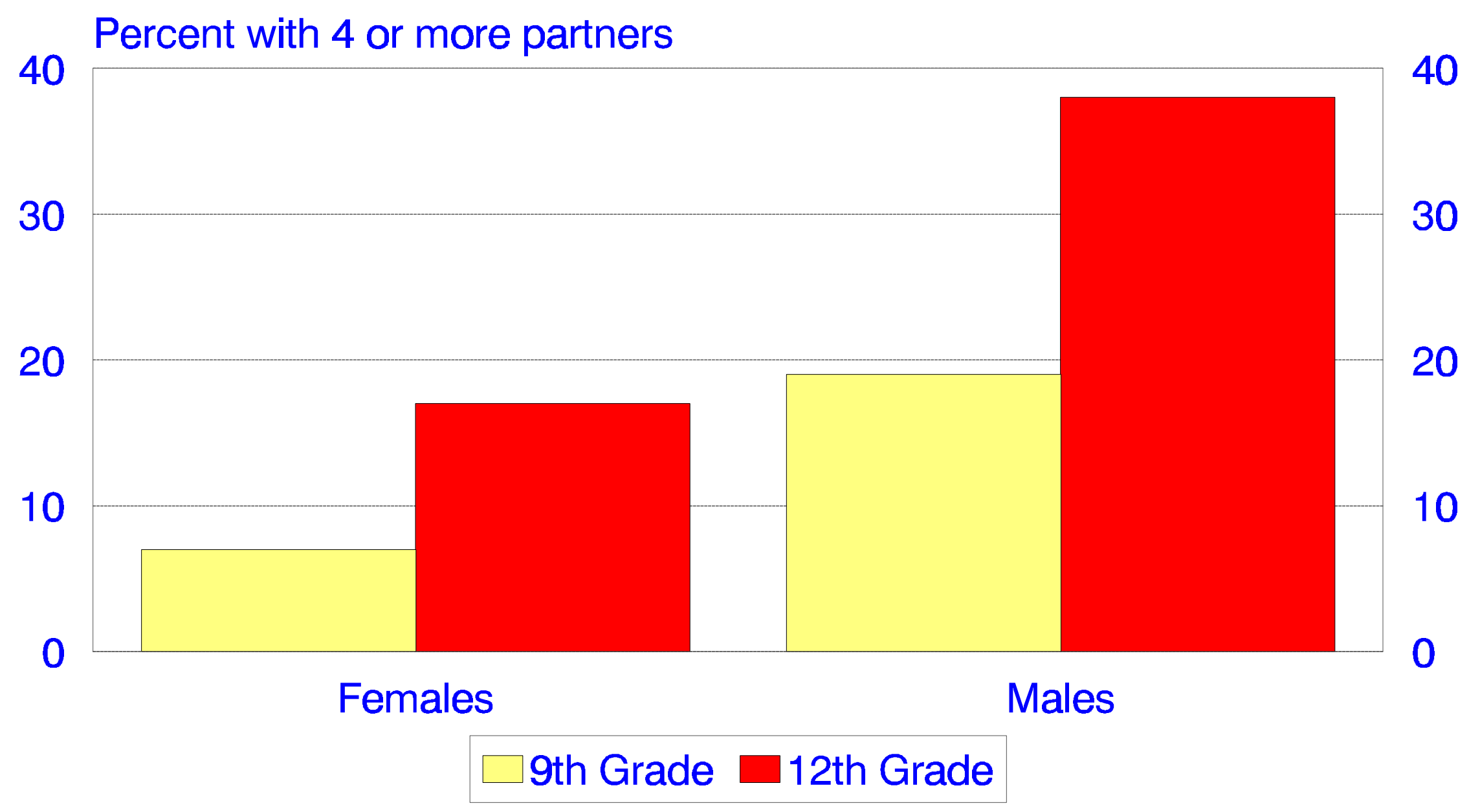




\section{Chart 4: Teen Sex More Middle-Class Females}

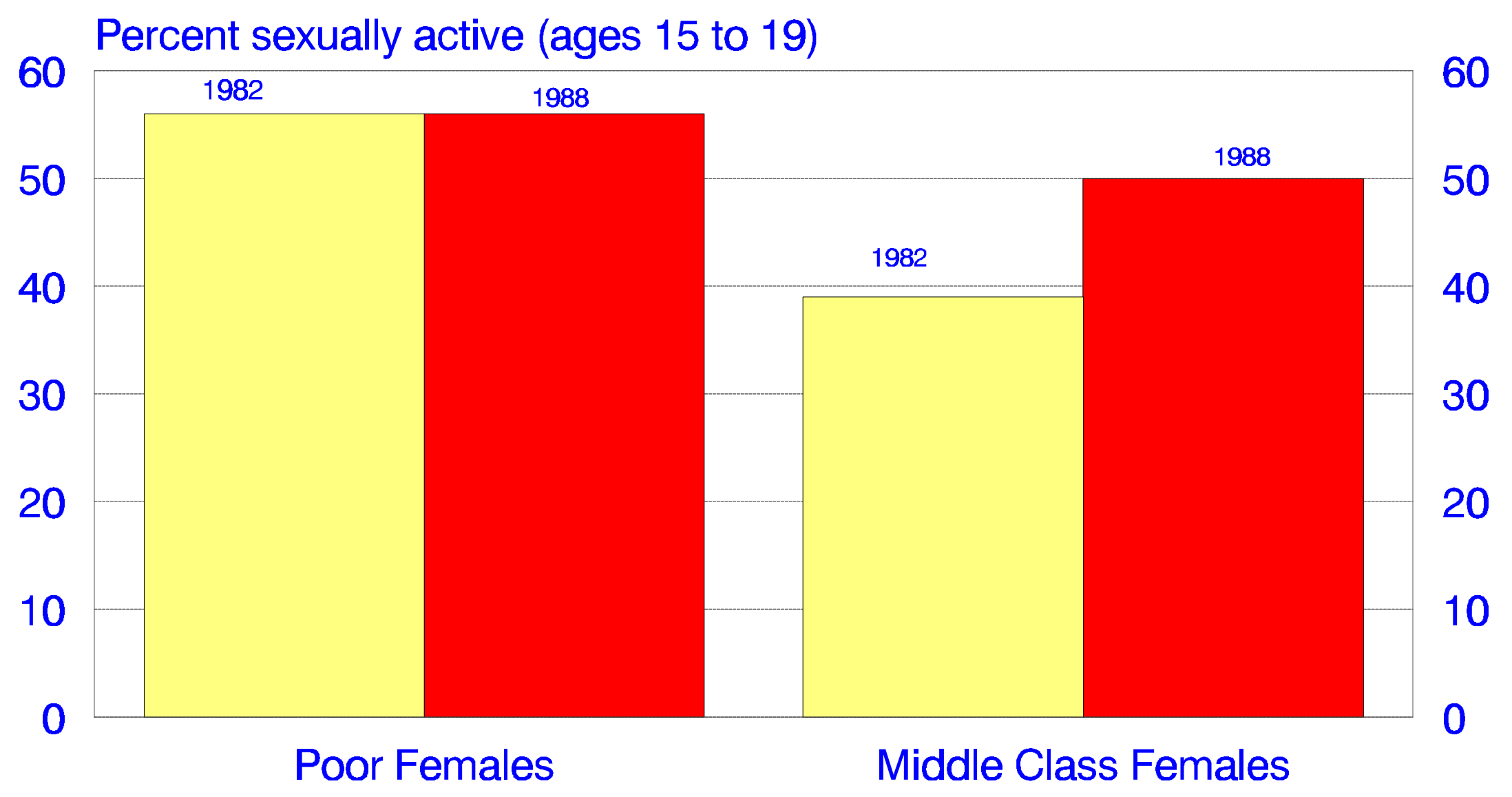




\section{Chart 5: Premarital Sexual Activity Females, By Age and Race}

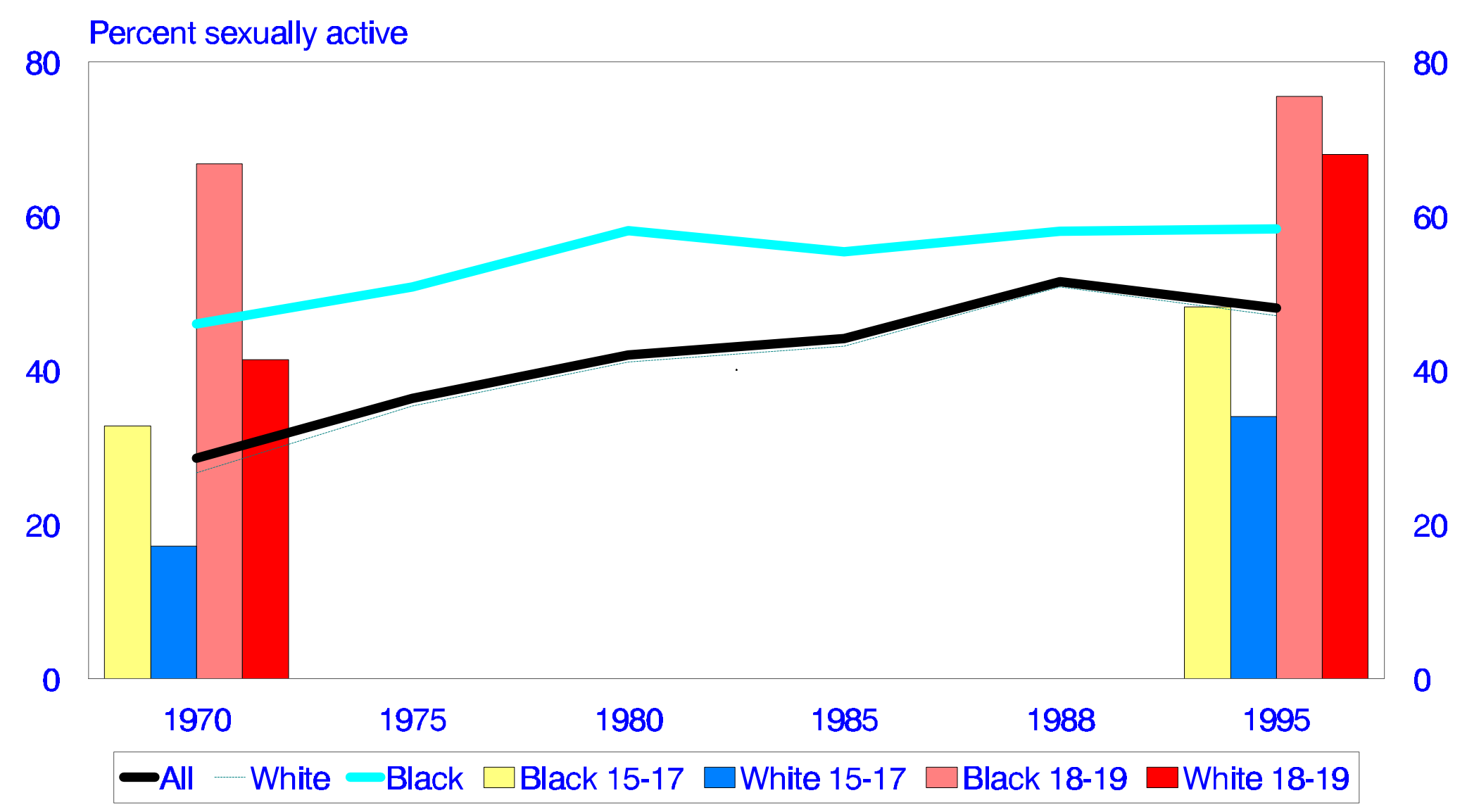




\section{Chart 6: Contraceptive Use at First Intercourse}

Females, by Race and Family Income

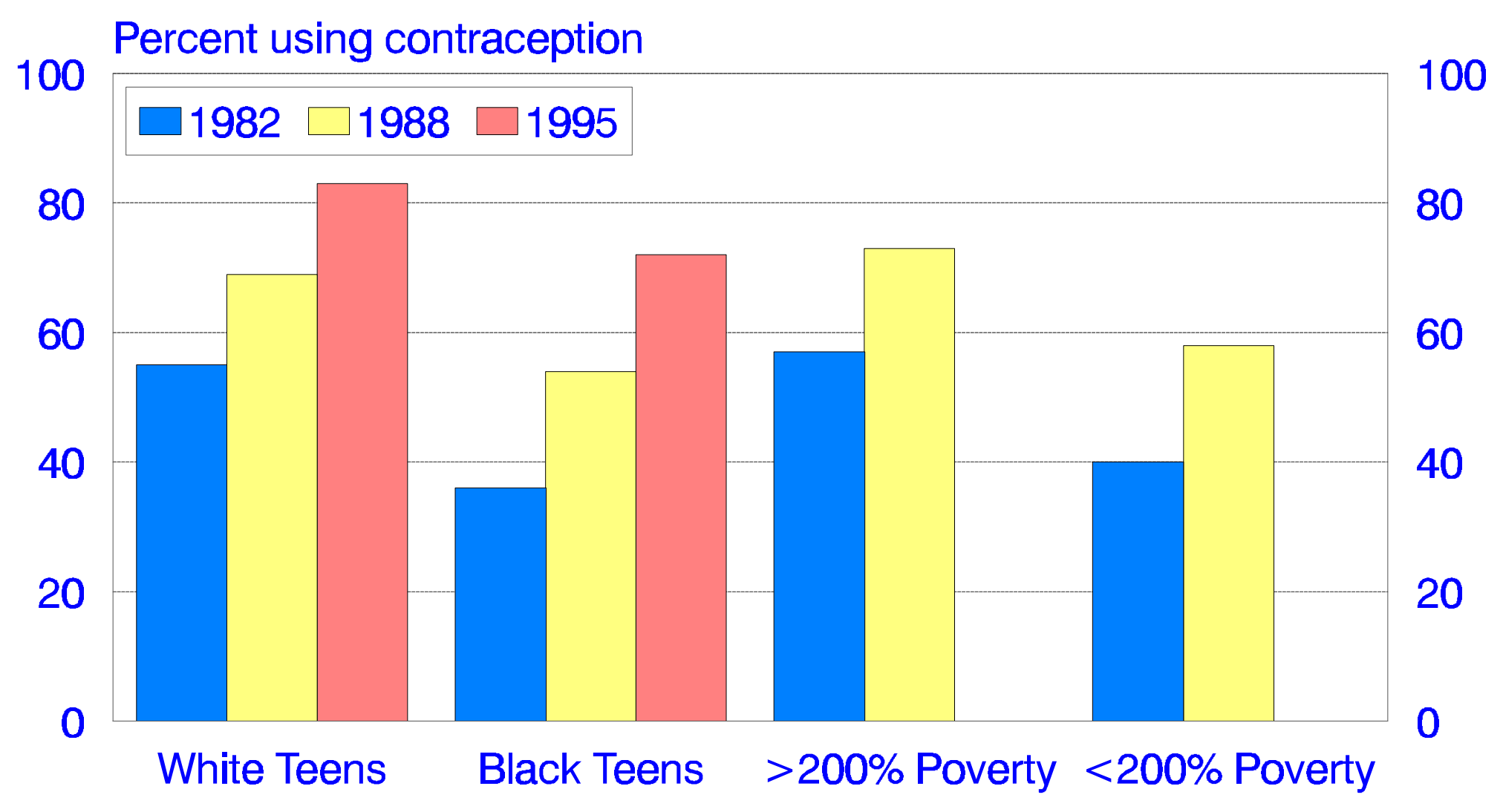




\section{Chart 7: Condom Use Sexually Active Men Ages 17-19}

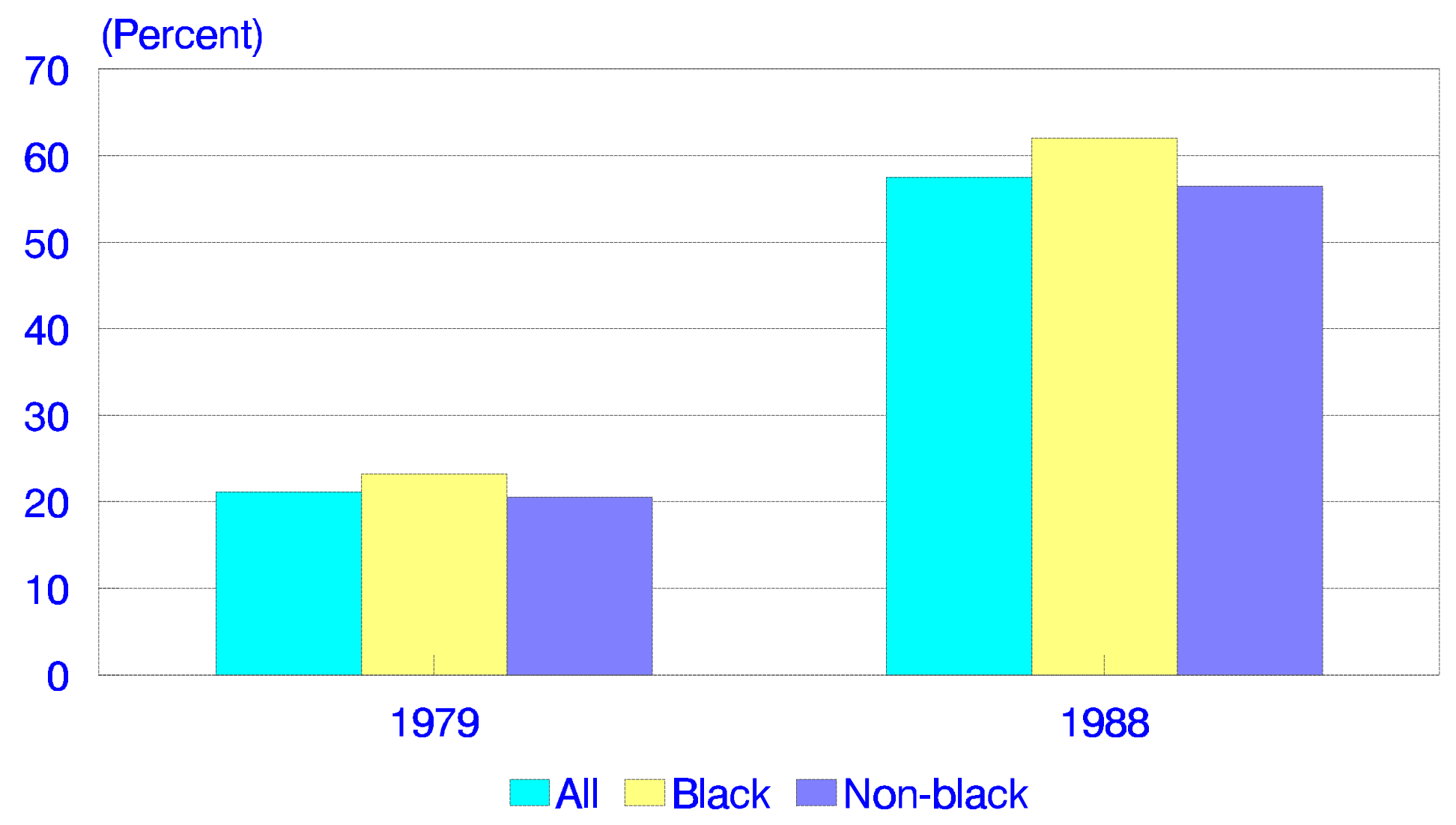

Source: Sonenstein, et. al., Family Planning Perspectives, vol. 21, no. 4 (July/August 1989) 


\section{Chart 8: Behind the Conception Index Females Ages 15 to 19}

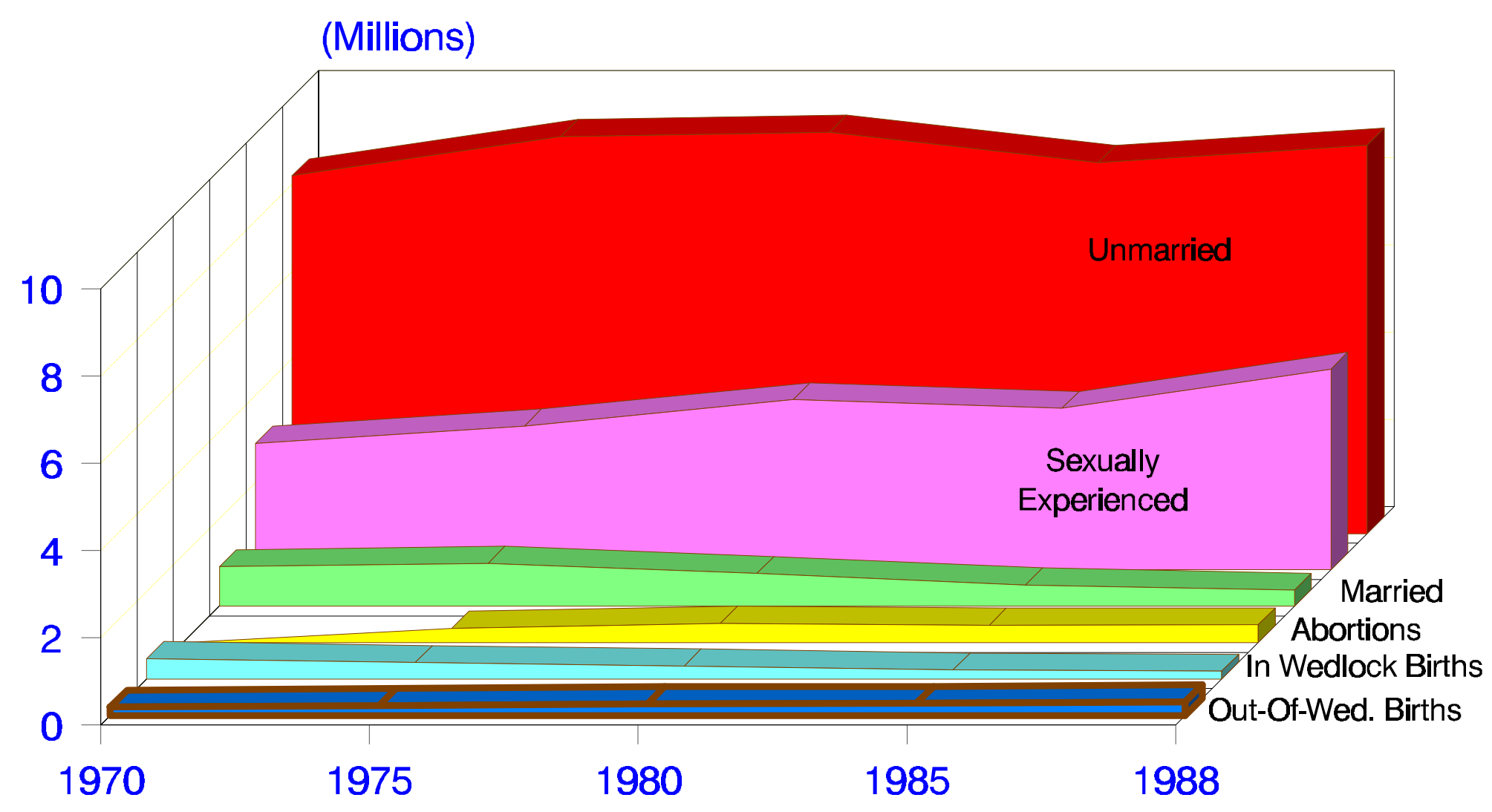




\section{Chart 9: Condom Use}

Sexually Active Female Teens

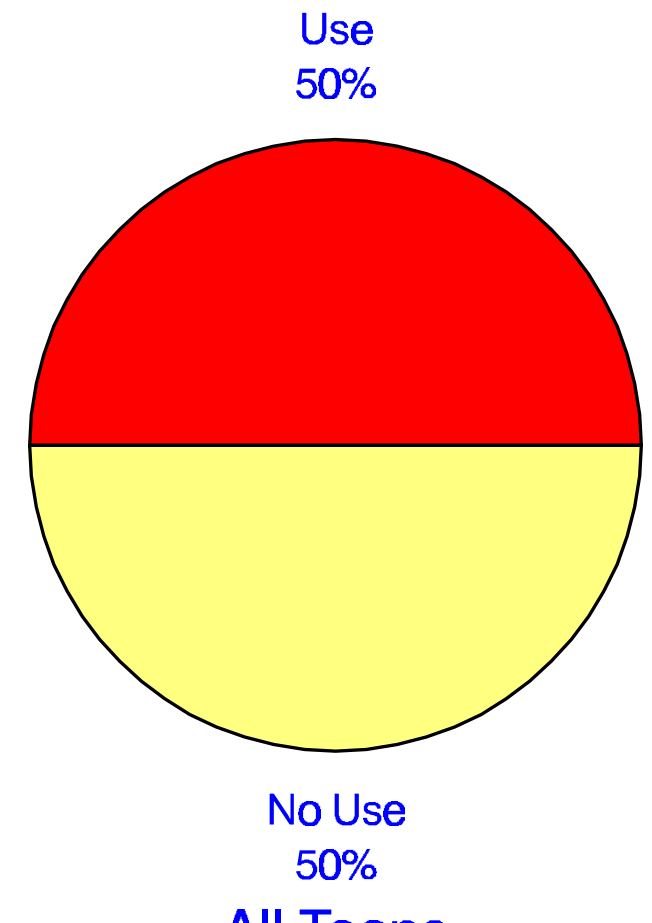

All Teens

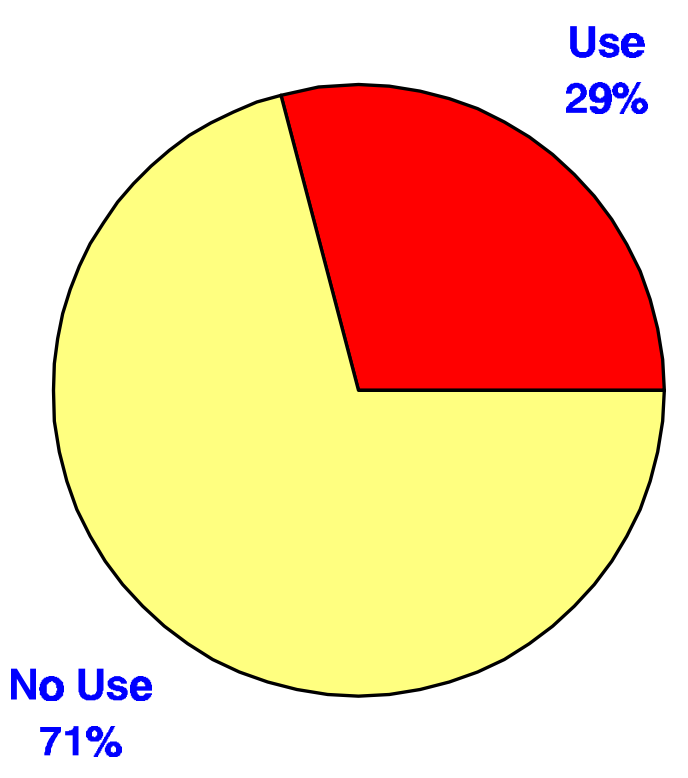

High-Risk-Behavior Teens 


\section{Chart 10: Early Sex and Risk-Taking Behaviors}

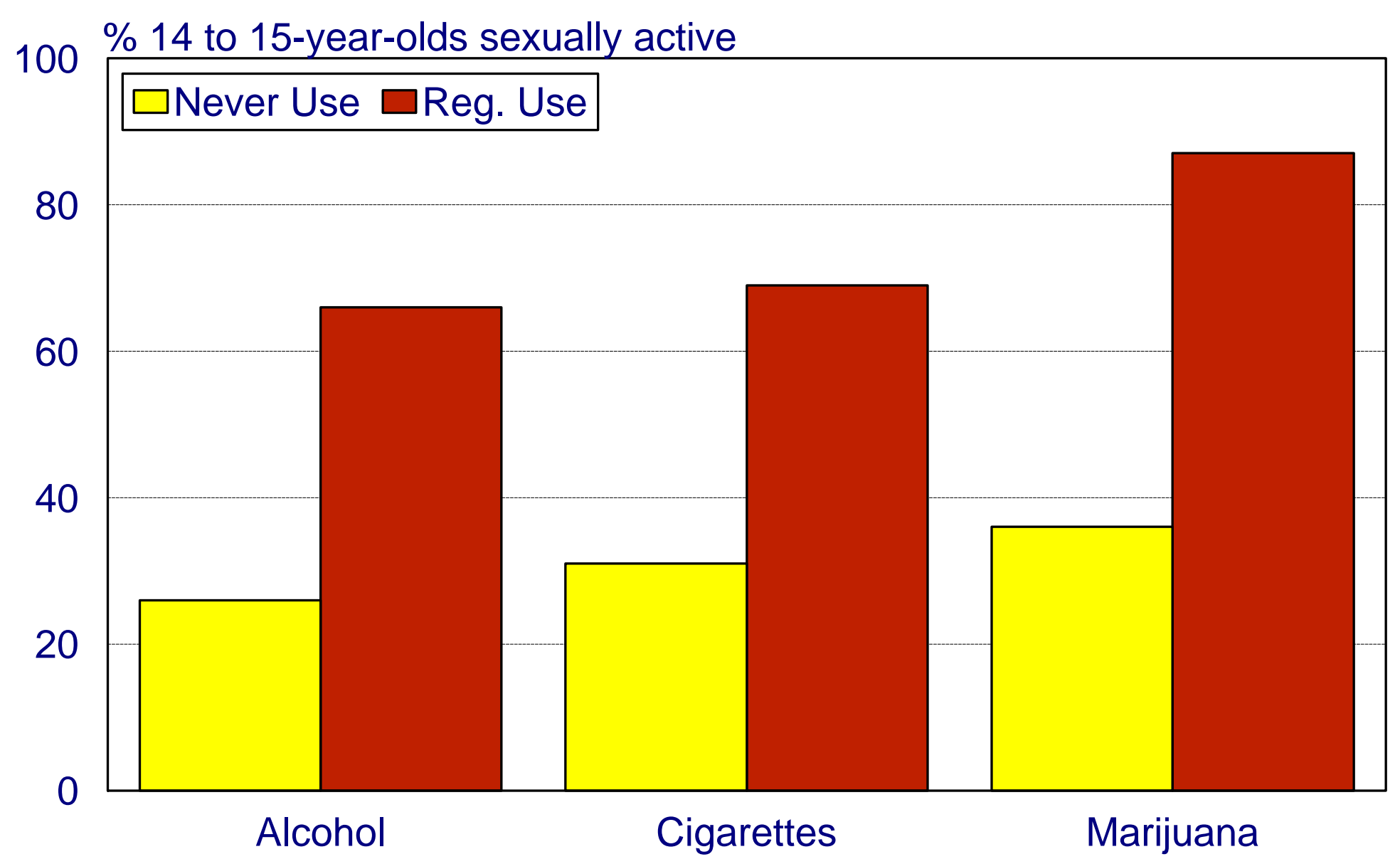

Source: Alan Guttmacher Institute 


\section{Chart 11: Contraceptive Failure Rates}

Percent experiencing failure within first 12 months

60

$\square$ Typical User $\square$ Teen >200\% Poverty $\square$ Teen <200\% Poverty

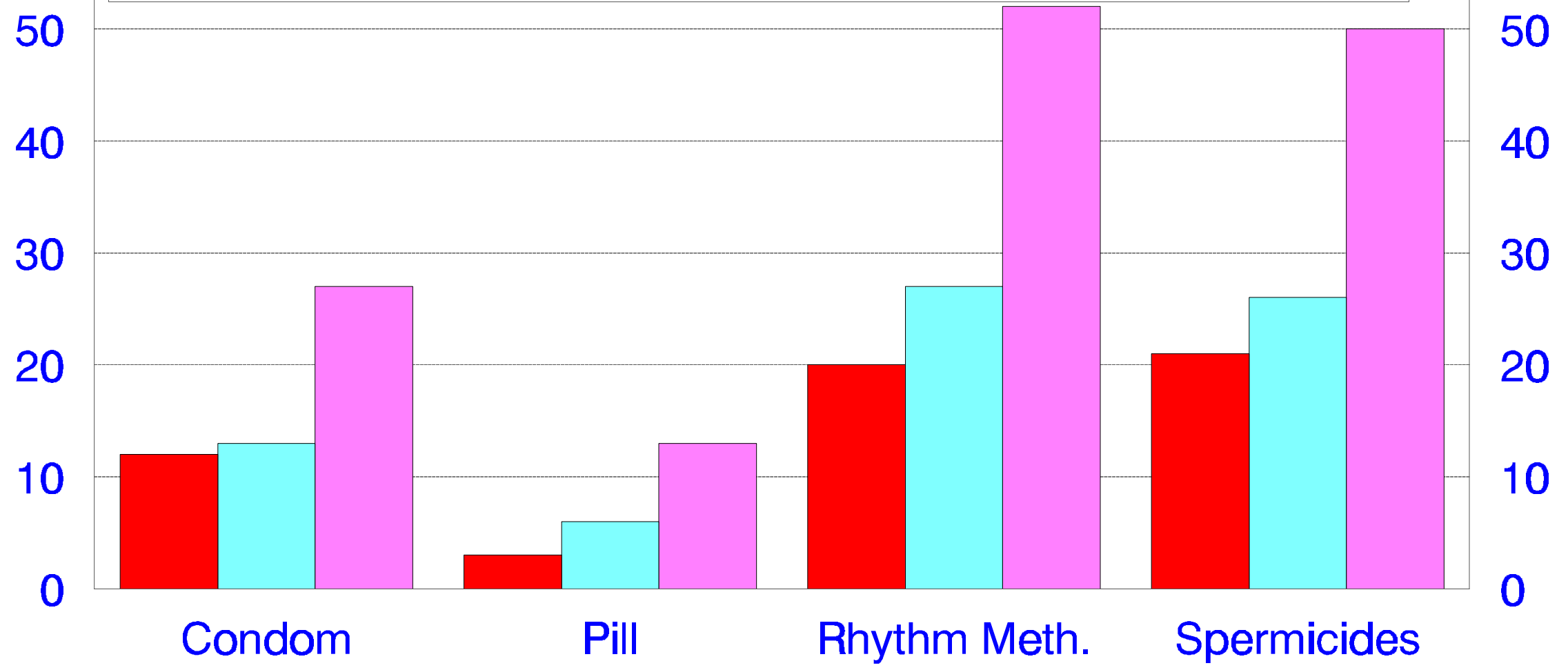




\section{Chart 12: Births to Teens Age Gap of Father, California, 1990}

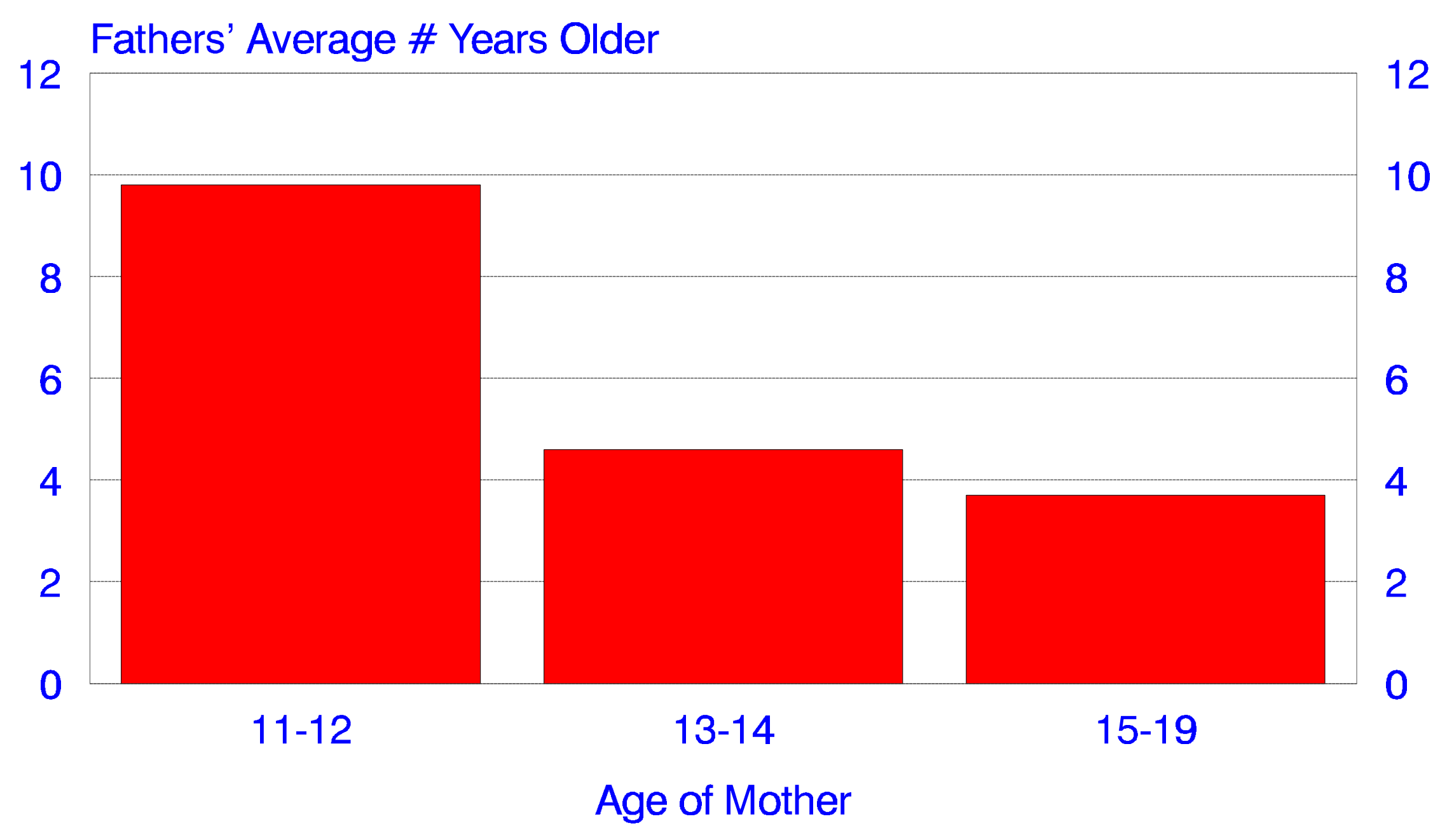




\section{Chart 13: Abortion Among Teenagers By Poverty Status}

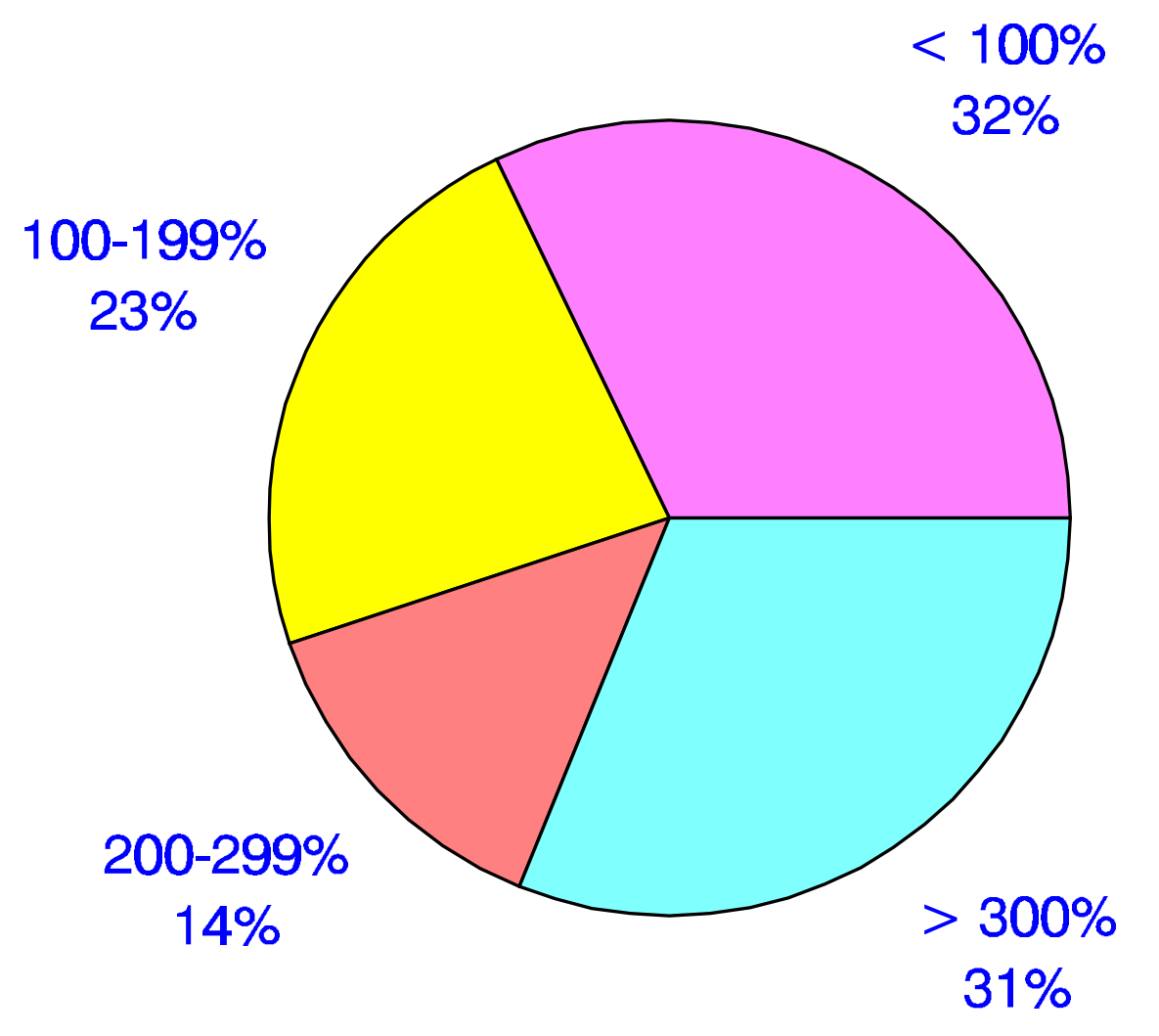




\section{Chart 14: Births to Teenagers Whites}

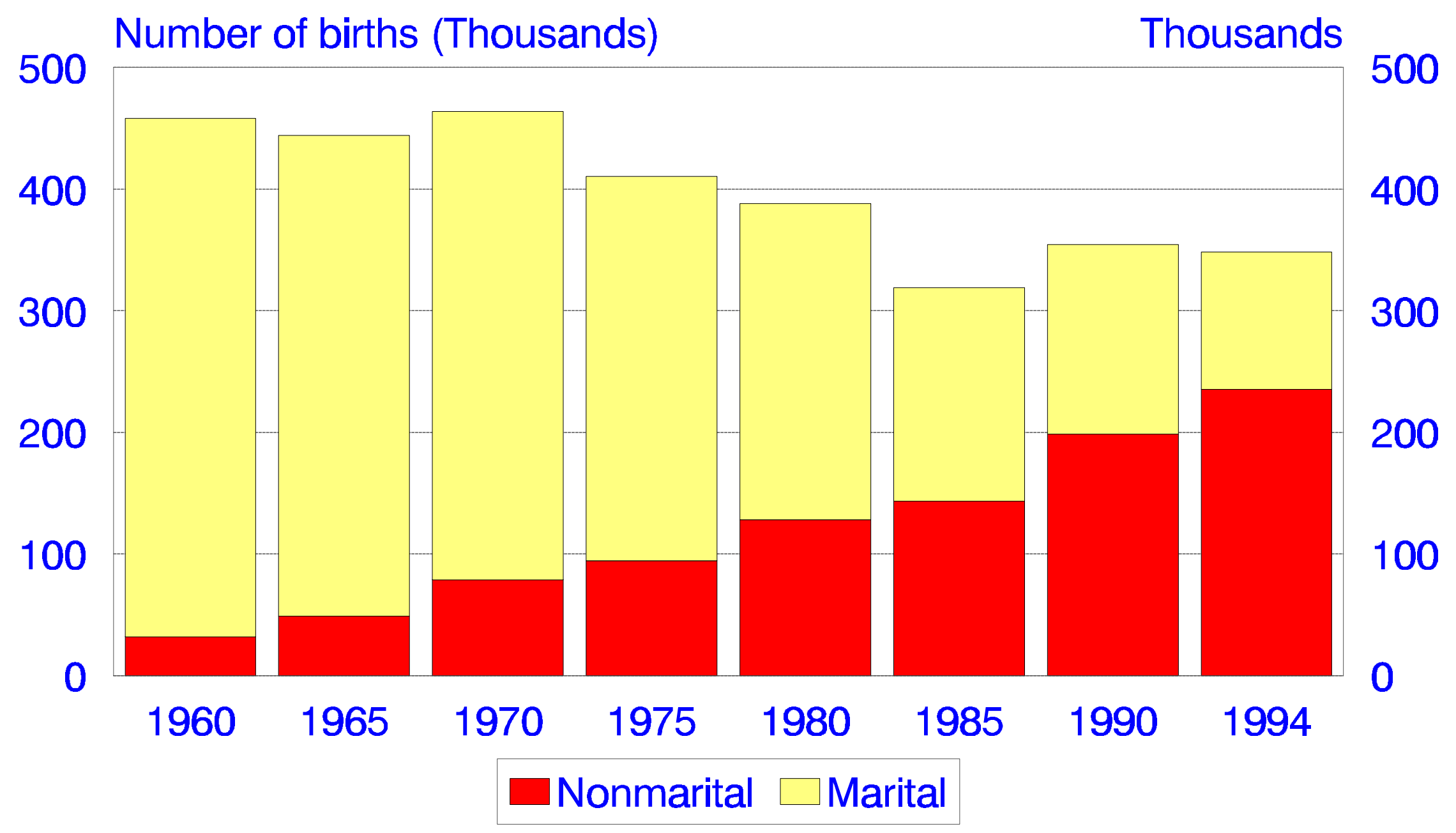




\section{Chart 15: Births to Teenagers Blacks}

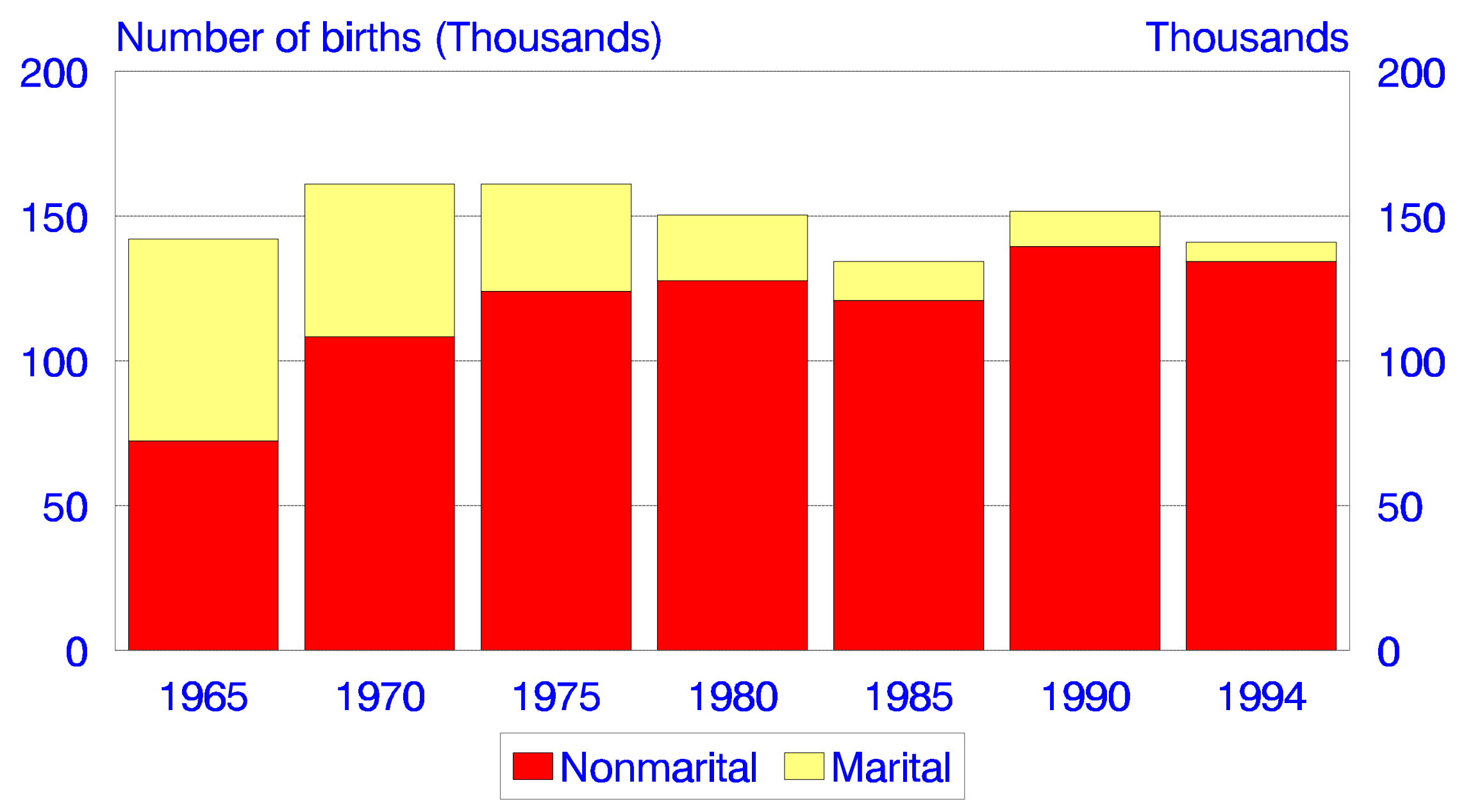




\section{Chart 16: Sexually Transmitted Diseases by Age}

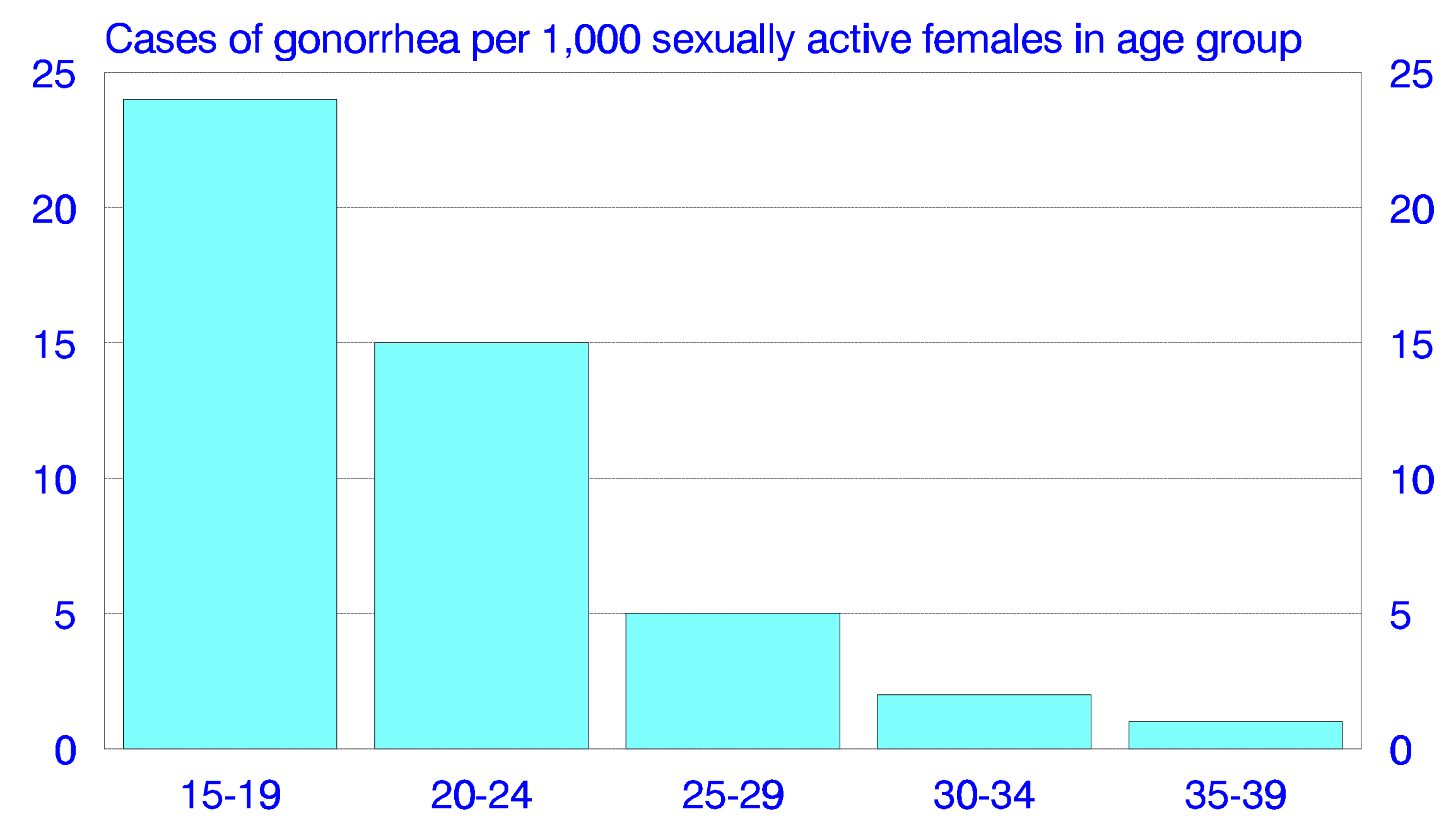




\section{Table 1: Teenage Mothers on AFDC}

\begin{tabular}{lll} 
Characteristics & $\begin{array}{l}\text { \% on within 1 yr. of } \\
\text { birth }\end{array}$ & $\begin{array}{l}\% \text { on within } 5 \text { yrs. of } \\
\text { birth }\end{array}$ \\
\hline All Teens & 28 & 49 \\
Married & 7 & 24 \\
Unmarried & 50 & 77 \\
White & 22 & 39 \\
Black & 44 & 76 \\
White, & 53 & 72 \\
Unmarried & & \\
Black, & 49 & 84 \\
Unmarried & &
\end{tabular}

